1. MBBS, MCPS, FCPS

Associate Professor Obstetrics \& Gynecology

Shaheed Muhtrama Benazir Bhutto

Medical College Layari, Karachi.

2. MBBS, FCPS

Assistant Professor Obstetrics and Gynecology

Hamdard Medical University, Karachi.

3. MBBS, FCPS

Assistant Professor Obstetrics and Gynecology

Dow University of Health Sciences, Karachi.

4. MBBS, MCPS, FCPS

Assistant Professor Paediatrics Shaheed Muhtrama Benazir Bhutto Medical College Layari, Karachi.

5. MBBS, FCPS

Assistant Professor Psychiatry

Dow International Medical College

Dow University of Health Sciences,

6. MBBS, MD

Associate Professor Medicine

Karachi Institute of Medical

Sciences,

Malir Cantonment, Karachi

Correspondence Address:

Dr. Nathumal Maheshwari

MBBS, MCPS, FCPS

Department of Paediatrics

Shaheed Muhtrama Benazir Bhutto

Medical College Layari, Karachi.

drnathumal@gmail.com

Article received on:

27/08/2019

Accepted for publication:

05/11/2019

\section{SERUM COBALAMIN STATUS OF PREGNANT WOMEN SUFFERING FROM GESTATIONAL DIABETES MELLITUS.}

\begin{abstract}
Saher Fatima1, Sadia Saeed ${ }^{2}$, Syeda Fariha Hasnny ${ }^{3}$, Nathumal Maheshwari ${ }^{4}$, Urooj Tabassum ${ }^{5}$,
\end{abstract} Arshad Ali ${ }^{6}$

ABSTRACT... Objectives: Determining serum cobalamin levels in Pregnant Women suffering from Gestational Diabetes mellitus (GDM) presenting at our tertiary care hospital. Study Design: Case control study. Setting: Department of Gynecology and Medicine, SMBB Medical College Layari General Hospital Karachi. Period: January 2016 to April 2017. Material \& Methods: Sample of 100 pregnant women in $2^{\text {nd }}$ and $3^{\text {rd }}$ trimester was selected into; 50 controls and 50 GDM cases through convenient sampling. GDM was defined as pregnant women with fasting blood sugar $\geq 100 \mathrm{mg} / \mathrm{dL}$. $5 \mathrm{ml}$ blood was collected; $3 \mathrm{ml}$ put into EDTA tubes for complete blood counts and $2 \mathrm{ml}$ for sera. Blood glucose was estimated by hexokinase method, HbA1c by colorimetric method and cobalamin by ECLIA assay method. SPSS software 21.0 (IBM, Inc USA) was used for data analysis using Student t-test and Chi-square test $(P \leq 0.05)$. Results: Age of control was $30.43 \pm 1.49$ years and $29.95 \pm 1.27$ years in cases. Gestational age was $33.67 \pm 2.69$ weeks in controls and $34.75 \pm 2.53$ weeks in cases. Control and cases shows serum cobalamin levels of $316.34 \pm 113.77 \mathrm{pg} / \mathrm{ml}$ and $253.5 \pm 121.32 \mathrm{pg} / \mathrm{ml}$ respectively $(\mathrm{P}=0.009)$. Serum cobalamin deficiency was noted in $68 \%$ of cases and $40 \%$ of controls $(P<0.05)$. Glycemic control was bad in majority of cases. Serum cobalamin shows inverse correlation with random blood glucose, fasting blood glucose and Glycated HbA1. Conclusion: We found low serum cobalamin levels in pregnant women suffering from gestational diabetes mellitus that showed inverse correlation with random and fasting blood glucose and glycemic control.

Key words: $\quad$ Gestational Diabetes Mellitus, Cobalamin, Glycemic Control.

Article Citation: Fatima S, Saeed S, Hasnny SF, Maheshwari N, Tabassum U, Ali A. Serum cobalamin status of pregnant women suffering from gestational diabetes mellitus. Professional Med J 2020; 27(5):1004-1010.

DOI: 10.29309/TPMJ/2020.27.05.4076

\section{INTRODUCTION}

Gestational diabetes mellitus (GDM) is defined as any degree of glucose intolerance and hyperglycemia first time observed during pregnancy. ${ }^{1}$ GDM complicates approximately $7 \%$ of pregnancies accounting for $>0.2$ million cases per annum. ${ }^{1-3}$

Prevalence of GDM ranges from 1-14\% of pregnancies. The variation depends on the population studied and diagnostic methodology of glucose testing. Previous studies ${ }^{2-4}$ form South East Asia reported GDM prevalence range of $4.2 \%$ to $26 \%$. However, a recent study showed GDM prevalence of $17.2 \%$ in pregnant female during second trimester. ${ }^{5}$

GDM is a serious metabolic disorder for mother and fetus. In mothers, the long term risk of DM is increased. Also the risk of metabolic syndrome and cardiovascular disease is increased in GDM. Pregnant GDM female are at increased risk of urinary tract infections, sepsis, pregnancy toxemia, and polyhydramnios. Incidence of premature child birth and cesarean section is increased too. Many of the fetal complications have been reported such as macrosomia, intrauterine death, congenital malformations, and spontaneous abortion. ${ }^{6}$

Risk of developing type $2 \mathrm{DM}$ is 7 times increased in subsequent pregnancies. ${ }^{7}$ Many risk factors have been implicated for developing GDM, such as multiparity, maternal age $\geq 25$ years and BMI $>30 \mathrm{Kg} / \mathrm{m}^{2}$ before pregnancy. ${ }^{8}$ 
Female suffering from GDM is prone to developing frank DM in next pregnancies, and post partum period. Female with history of macrosomia $(>4.0 \mathrm{~kg})$ of fetus, positive family history of DM, Asian and African ethnicities are at high risk of developing GDM in subsequent pregnancies. ${ }^{1-7}$

Vitamin cobalamin (vitamin $B_{12}$ ) is an essential nutrient for the cell growth, maturation and cell division along with folic acid. Vitamin cobalamin plays role in the red blood cell production, neuronal growth and myelination of brain., ${ }^{1,5,8}$ Vitamin cobalamin deficiency is prevalent in the country. ${ }^{9}$

10 Dietary vitamin cobalamin deficiency or due to increased demands as during pregnancy, it manifests as grave medical symptoms and complications in the mother and fetus. Delayed cobalamin replacement presents with rapid appearance of symptoms within short time period. Vitamin cobalamin deficiency may be treated by high dose oral supplements or parenteral route. ${ }^{11}$ Pregnant women are at high risk of vitamin cobalamin deficiency because of poor nutritional status and high cell turnover in the body. Rapidly growing fetus consumes more vitamin cobalamin from the maternal blood thus putting them on increased risk of this vitamin that may be deficient in the maternal diet. If dietary requirements are not met, vitamin cobalamin deficiency ensues. ${ }^{12}$

Vitamin cobalamin deficiency manifests as glossitis, stomatitis, red buffy tongue, and malabsorption due to villi atrophy. Mucositis is also noted. Peripheral blood smear shows macrocytic erythrocytes with or without anemia. Poikilocytosis, anisocytosis, ovalocytosis, hypersegmented neutrophils and pancytopenia may occur. ${ }^{12,13}$

Fetus may develop intrauterine growth retardation, fatty liver disease and poor mental development due to defective myelination in the central nervous system. Such babies are prone to developing a multitude to chronic diseases in future such diabetes mellitus (DM), depression, cardiovascular disorders and even cancer. ${ }^{12}$ Currently, the issue of vitamin cobalamin deficiency and GDM has been hotly hinted in medical literature ${ }^{12,13}$, hence there is a need to explore this association of Vitamin cobalamin and GDM in our indigenous population. The present study was planned to explore the Vitamin cobalamin status in Pregnant Women with Gestational Diabetes mellitus presenting at our tertiary care hospital.

\section{MATERIAL \& METHODS}

The present case control study was conducted at the Department Gynecology and Obstetrics, Shaheed Muhtrama Benazir Bhutto Medical College Layari General Hospital Karachi, Sindh, Pakistan from January 2016 to April 2017. Ethical approval of research protocol was applied for the ERC (ethical review committee). Sample size was calculated by 'sampling for proportions'. Sample size was calculated to be 95 by using $5 \%$ a-level of significance and power of test of $90 \%$ at an expected $\%$ of vitamin cobalamin deficiency in GDM subjects as $51 \%$ and without GDM as $21.9 \% .^{7}$ But in order to increase the power, 100 subjects were divided into 2 groups; Group 1cases of gestational diabetes mellitus and Group 2 - controls. Cases were selected by convenient sampling. GDM cases and control were selected according to the inclusion and exclusion criteria at the booked antenatal clinics of Layari General Hospital. GDM was defined according to the American Diabetes Association (ADA) criteria of $75 \mathrm{~g}$ OGTT. ${ }^{14}$ GDM was defined as pregnant women with fasting blood sugar $\geq 100 \mathrm{mg} / \mathrm{dL}$. ${ }^{14}$

Gestational age (GA) was calculated by recalling the first day of LMP (last menstrual period). Gravida was defined as total number of pregnancies regardless of the conception outcome. GDM cases were diagnosed as pregnant women with fasting blood sugar $\geq 100 \mathrm{mg} / \mathrm{dL}$ as cited. ${ }^{14} \mathrm{~A}$ sample of 50 GDM patients were tagged cases. Similar number of age and gender matched pregnant female without diabetes mellitus were diagnosed as controls $(n=50)$. Inclusion criteria for controls were pregnant female in $2^{\text {nd }}$ and $3^{\text {rd }}$ trimester of pregnancy with normal blood fasting sugar levels. Inclusion criteria for cases were defined as; $2^{\text {nd }}$ and $3^{\text {rd }}$ trimester of pregnancy of age 25 - 40 years who remembered the exact 
LMP date. And GDM patients being treated with metformin are strictly excluded. Pregnant female who suffered from abdominal tuberculosis, pancreatic disease, Gastroesophageal reflux disorder, strict vegetarians, renal disease, and chronic liver disease were excluded. Pregnant female using multivitamin pills since beginning of first trimester were excluded. Volunteers were informed about the purpose of study and willing volunteers were asked to sign the consent form. Findings of research interest were noted in a proforma of study protocol designed by the researcher. Patient history, gravidity, LMP, GA Clinical problem, and blood findings were noted. Confidentiality of patient's records was ensured. Patients were informed that the results and biodata will never be publicized and shall remain confidential. Volunteers were asked for blood sampling. Willing participants were informed that the blood sampling will cause no harm and blood will be used only for the testing of glucose and vitamin levels. Participants were intimated that the laboratory expense will be paid by the researcher not by the patients.

Height, weight and body mass index were calculated. Systemic blood pressure was measured by mercury sphygmomanometer. Willing volunteers were asked to lie on examination couch. A tourniquet was tightly applied above the cubital fossa to make the vein prominent. Skin over prominent vein was sterilized with alcohol swab. Disposable syringe (BD, USA) was used for venesection to draw $5 \mathrm{ml}$ blood. $3 \mathrm{ml}$ of blood sample was put into EDTA tubes for complete blood counts. Fasting blood sugar was estimated by glucose hexokinase method and hemoglobin A1 glycosylated (HbA1c) by Colorimetric method. Serum cobalamin levels were estimated by using the ECLIA (Electro-chemiluminescence immunoassay) method.

Serum cobalamin levels were defined as deficiency $<200 \mathrm{pg} / \mathrm{mL}$; marginal deficiency $200-299 \mathrm{pg} / \mathrm{mL}$ and normal cobalamin at $\geq 300$ $\mathrm{pg} / \mathrm{mL} .{ }^{15}$ Data variables were typed on Excel sheet and copied to SPSS software 21.0 (IBM, Inc USA). Age, gestational age, gravida, fasting blood sugar, $\mathrm{HbA} 1 \mathrm{c}$ and serum cobalamin were analyzed by Student's t-test. Serum cobalamin categories of deficiency, marginal deficiency and normal were cross tabulated using Chi-square test. Pearson's correlation was used for the correlation of serum cobalamin with RBG, FBG, $\mathrm{HbA} 1 \mathrm{c}$ and gestational age. All data variables were analyzed at $95 \%$ confidence interval ( $P \leq$ 0.05).

\section{RESULTS}

Age of control was $30.43 \pm 1.49$ years and $29.95 \pm 1.27$ years of cases. Gestational age and gravida in control and cases were matched as shown in Table-l. Gestational age was $33.67 \pm 2.69$ weeks in controls and $34.75 \pm 2.53$ weeks in GDM cases.

All of the control $(2.44 \pm 0.50)$ and GDM cases $(2.42 \pm 0.49)$ were gravida 2 or 3 . Hemoglobin $(\mathrm{g} / \mathrm{dl})$, hematocrit (\%), RBC counts (million $/ \mu \mathrm{L}$ ) and Platelets (million $/ \mu \mathrm{L}$ ) are shown in Table-l. Random blood glucose (RBG) was noted as $136.58 \pm 9.43 \mathrm{mg} / \mathrm{dl}$ in controls and $220.16 \pm 82.69$ $\mathrm{mg} / \mathrm{dl}$ in cases. Fasting blood glucose (FBG) in control and cases was noted as $88.56 \pm 7.87$ and $155.67 \pm 48.73 \mathrm{mg} / \mathrm{dl}$ respectively $(P=0.0001)$. Glycated $\mathrm{HbA}_{1}$ in cases was $7.66 \pm 1.33 \%$ compared to $5.43 \pm 0.58 \%$ in controls. Serum cobalamin (mean \pm SD) in control and cases were noted as $316.34 \pm 113.77$ (range 113-513.1) pg/ $\mathrm{ml}$ and $253.5 \pm 121.32$ (range $110-513.5) \mathrm{pg} / \mathrm{ml}$ $(P=0.009)$ (Table-II). Sufficient serum cobalamin $(\geq 300 \mathrm{pg} / \mathrm{mL})$ was found in $30(60 \%)$ controls compared to $16(32 \%)$ GDM cases.

Marginal deficiency (cobalamin 200- $299 \mathrm{pg} / \mathrm{mL}$ ) was noted in $11(22 \%)$ of cases compared to 15 $(30 \%)$ of controls. $23(46 \%)$ of cases revealed deficient serum cobalamin $(<200 \mathrm{pg} / \mathrm{mL})$ compared to $5(10 \%)$ in controls. Total $68 \%$ cases and $40 \%$ controls revealed serum cobalamin deficiency (Table-III). $(P<0.05)$. Serum cobalamin shows significant inverse correlation with $R B G(r=$ -0.196, $P=0.008), F B G(r=-0.226, P=0.001)$ and $\mathrm{HbA1c}(r=-0.361, \mathrm{P}=0.0001)$ as shown in TableIV. Figures-1-3 show the graphical distribution of negative correlation of serum cobalamin. 


\begin{tabular}{|l|c|c|c|}
\hline & Control & Cases & P-Value \\
\hline Age (years) & $30.43 \pm 1.49$ & $29.95 \pm 1.27$ & 0.086 \\
\hline Gestational age & $33.67 \pm 2.69$ & $34.75 \pm 2.53$ & 0.091 \\
\hline Gravida & $2.44 \pm 0.50$ & $2.42 \pm 0.49$ & 0.889 \\
\hline Hematocrit (Hct.) (\%) & $38.01 \pm 3.31$ & $38.12 \pm 3.11$ & 0.279 \\
\hline Hemoglobin $(\mathrm{g} / \mathrm{dl})$ & $10.90 \pm 0.57$ & $10.76 \pm 0.71$ & 0.739 \\
\hline RBC counts (million/ $/ \mathrm{LL})$ & $3.23 \pm 0.43$ & $3.20 \pm 0.46$ & 0.192 \\
\hline Platelet $(\mathrm{million} / \mu \mathrm{L})$ & $3.72 \pm 0.40$ & $3.62 \pm 0.41$ & 0.0001 \\
\hline Random Glucose $(\mathrm{mg} / \mathrm{dl})$ & $136.58 \pm 9.43$ & $220.16 \pm 82.69$ & 0.0001 \\
\hline Fasting Glucose $(\mathrm{mg} / \mathrm{dl})$ & $88.56 \pm 7.87$ & $155.67 \pm 48.73$ & 0.0001 \\
\hline Glycemic control (HbA1c \%) & $5.43 \pm 0.58$ & $7.66 \pm 1.33$ & 0.009 \\
\hline \multicolumn{2}{|c|}{ Table-l. Demographic features and biochemical blood findings } \\
\hline
\end{tabular}

\begin{tabular}{|l|c|c|}
\hline \multicolumn{1}{|c|}{ Serum cobalamin $(\mathbf{p g} / \mathbf{m l})$} & Control & Cases \\
\hline Mean $(\mathrm{pg} / \mathrm{ml})$ & 316.34 & 253.50 \\
\hline Standard Deviation & 113.77 & 121.32 \\
\hline Standard Error Mean & 16.09 & 17.15 \\
\hline 95\% Confidence Interval & & \\
$-\quad$ Lower & 16.16 & 16.15 \\
$-\quad$ Upper & 109.51 & 109.52 \\
\hline Range $(\mathrm{pg} / \mathrm{ml})$ & $113-513.1$ & $110-513.5$ \\
\hline t-value & & 2.67 \\
\hline P-value & & 0.009 \\
\hline
\end{tabular}

Table-II. Serum cobalamin in control and cases

\begin{tabular}{|l|c|c|c|c|}
\hline Serum Cobalamin & Control & Cases & X'-Value & P-Value \\
\hline$\geq 300 \mathrm{pg} / \mathrm{mL}$ & $30(60 \%)$ & $16(32 \%)$ & & \\
\hline $200-299 \mathrm{pg} / \mathrm{mL}$ & $15(30 \%)$ & $11(22 \%)$ & \multirow{2}{*}{0.0001} \\
\hline$<200 \mathrm{pg} / \mathrm{mL}$ & $5(10 \%)$ & $23(46 \%)$ & & \\
\hline Total & 50 & 50 & & \\
\hline
\end{tabular}

Table-III. Serum cobalamin in control and cases

\begin{tabular}{|l|c|c|}
\hline & r-value & P-Value \\
\hline Age & -0.099 & 0.17 \\
\hline Gestational Age & -0.064 & 0.089 \\
\hline RBS & -0.196 & 0.008 \\
\hline FBS & -0.226 & 0.001 \\
\hline HbA1c & -0.361 & 0.0001 \\
\hline
\end{tabular}

Table-IV. Pearson's correlation of serum cobalamin in cases

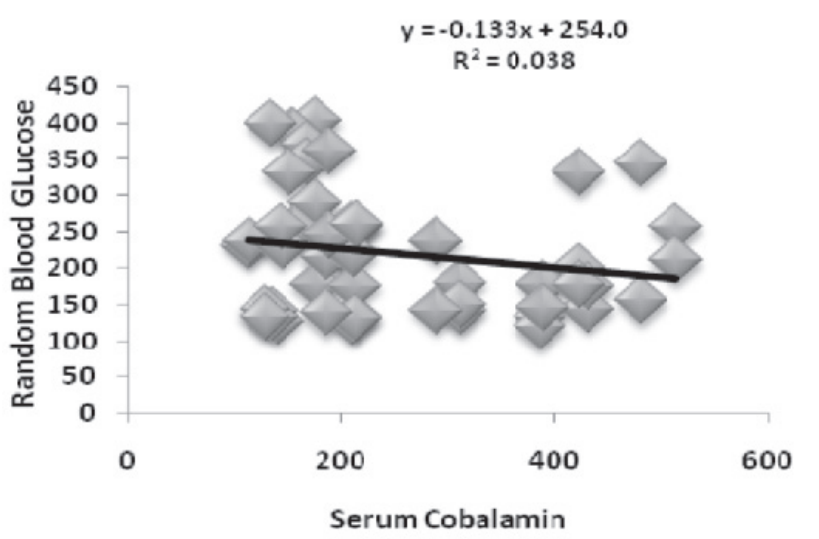

Figure-1. Scatter plot showing negative correlation of serum cobalamin and random blood glucose

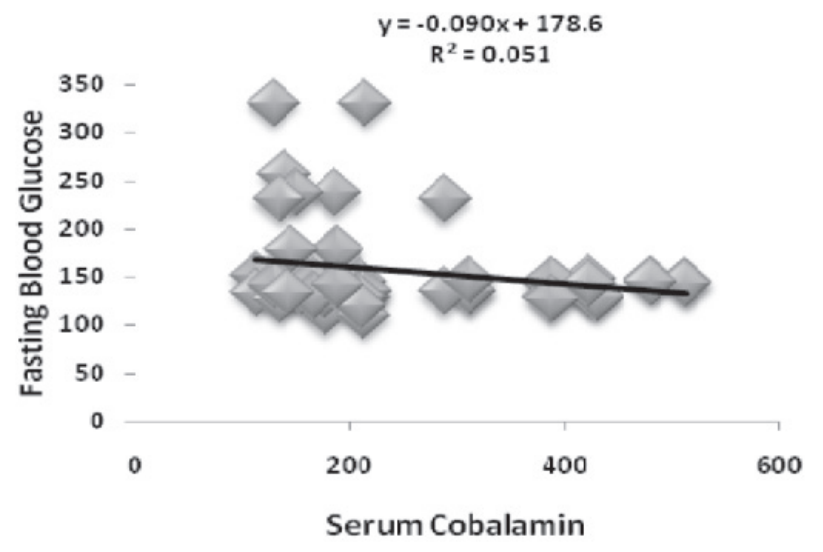

Figure-2. Scatter plot showing negative correlation of serum cobalamin and Fasting blood glucose 


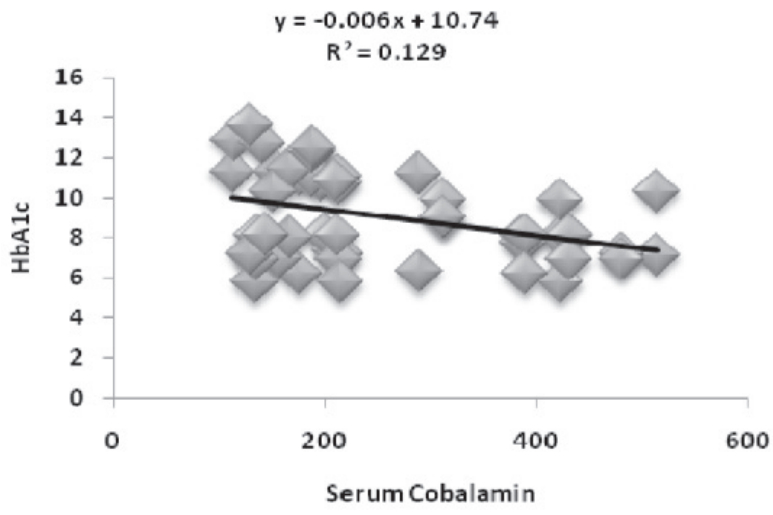

Figure-3. Scatter plot showing negative correlation of serum cobalamin and Glycemic control (HbA1c)

\section{DISCUSSION}

The present hospital based study reports serum cobalamin deficiency in $68 \%$ of gestational diabetes mellitus (GDM) cases and $40 \%$ of controls. Other noteworthy finding of present study is negative correlation of serum cobalamin with random $(r=-0.196, p=0.008)$ and fasting blood glucose $(r=-0.226, p=0.001)$ and glycated hemoglobin $(r=-0.361, p=0.0001)$. The findings of low serum cobalamin are in agreement with previous studies. $7,13,16-18$

The Milman et $\mathrm{al}{ }^{16}$ conducted a longitudinal study on the cobalamin levels among pregnant women and proved low cobalamin in normal pregnancies. The finding of low serum cobalamin in gestational diabetes mellitus (GDM) was reported by a previous study from India. ${ }^{17}$

They reported positive link of serum cobalamin deficiency with insulin resistance, adiposity and gestational diabetes mellitus. Krishnaveni et a/ $/^{17}$ further added that the risk of GDM is twice more frequent pregnant women with cobalamin deficiency than cobalamin non-deficient pregnant women. The findings of above study support the serum cobalamin deficiency in GDM of present study. Few years later, the Knight et al. (2015) ${ }^{18}$ examined the British cohort of pregnant women for serum cobalamin. They ${ }^{18}$ studied a cohort of white British pregnant women of different ethnicity with different dietary habits, nutritional status and livings standards of society.
They $^{18}$ reported serum cobalamin was low in pregnant women and revealed inverse correlation of serum cobalamin with fasting blood glucose $(r=-0.09 ; p=0.006)$ similar to present study. The findings of Knight et al ${ }^{18}$ are in full agreement with present study as negative correlation of serum cobalamin with random $(r=-0.196, p=0.008)$ and fasting blood glucose $(r=-0.226, p=0.001)$ and Glycated hemoglobin $(r=-0.361, p=0.0001)$ was noted. A year later, a UK based retrospective study by Sukumar et $a /{ }^{13}$ proved the link of low serum cobalamin in pregnant women suffering from GDM and regression analysis model revealed a 2.59 times higher odds of developing GDM in serum cobalamin deficient pregnant women. ${ }^{13}$

The findings of Sukumar et $\mathrm{al}^{13}$ are in keeping with the observations of present study. A recent study by Ambreen et al $(2017)^{7}$ analyzed the serum cobalamin levels in pregnant and reported $67 \%$ deficiency of serum cobalamin in GDM and $39 \%$ of controls. The findings of Ambreen et al $(2017)^{7}$ are validated by the present study that observes serum cobalamin deficiency in $68 \%$ of gestational diabetes mellitus (GDM) cases and $40 \%$ of controls. The Ambreen et al (2017) ${ }^{7}$ further noted negative correlation of serum cobalamin fasting blood glucose $(\beta=-0.29, p=0.004)$, gravidity $(\beta=-0.28, p=0.01)$ and gestational age $(\beta=-0.57, p=0.21)$. The above findings are comparable to the negative correlation of serum cobalamin with random $(r=-0.196, p=0.008)$ and fasting blood glucose $(r=-0.226, p=0.001)$ and Glycated hemoglobin $(r=-0.361, p=0.0001)$ of present study. Hence the findings of present study are worth reporting for future studies. Serum cobalamin deficiency is prevalent ${ }^{9,10}$ in the country due to nutritional deficiency added by economical constraints putting the pregnant ladies and children at highest risk.

Hence the finding of $40 \%$ cobalamin deficiency of present study is justified in the present scenario of nutritional deficiencies particularly in the developing countries. Many of previous studies $^{19-21}$ have attributed the serum cobalamin deficiency in diabetics to the metformin therapy but metformin intake was an exclusion criterion in the present study. Negative correlation of 
serum cobalamin with RBG, FBG, and $\mathrm{HbA} 1 \mathrm{c}$ is important finding that show the glycemic control will be deviated more to abnormal side with concomitant cobalamin deficiency in pregnant women suffering from GDM. Serum cobalamin levels should be closely monitored for prevention of materno-fetal complications. Intrauterine life of fetal metabolic programming may adversely affect through epigenetic modifications making the fetus prone to chronic disease in adult life. ${ }^{22,23}$ Timely correction of cobalamin deficiency and diabetic management of GDM may prevent the adverse feto-maternal outcomes. As the bad glycemic control is also a risk factor for the materno-fetal outcome hence this needs to be addressed by the treating obstetricians and physicians. The findings of present study in the light of national and international literature are worth to report. The limitations of present study include - first; small sample size, second; anthropometric data of pre- pregnancy serum cobalamin, nutritional status and dietary habits are not clear, third; cross sectional study design, hence findings cannot be generalized. However, the strength of study lays in its prospective study design, and exclusion and inclusion criteria.

\section{CONCLUSION}

We found low serum cobalamin levels in pregnant women suffering from gestational diabetes mellitus and showed inverse correlation with random and fasting blood glucose and glycemic control. The present hospital based study reports $68 \%$ deficiency of serum cobalamin in gestational diabetes mellitus. Cobalamin supplements should be recommended to this particular population at risk of improving maternal, neonatal and child outcome, giving emphasis on neurological processes and epigenetic modification.

\section{Copyright@ 05 Nov, 2019.}

\section{REFERENCES}

1. Mirghani Dirar A, Doupis J. Gestational diabetes from A to Z. World J Diabetes 2017; 8(12): 489-511.

2. Bibi S, Saleem U, Mahsood N. The frequency of gestational diabetes mellitus and associated risk factors at Khyber Teaching Hospital, Peshawar. J Postgrad Med Inst (Peshawar Pakistan) 2015; 29: 44-6.
3. Iqbal R, Rafique G, Badruddin S, Qureshi R, Cue R, Gray-Donald K. Increased body fat percentage and physical inactivity are independent predictors of gestational diabetes mellitus in South Asian women. Europ J Clin Nutr 2007; 61: 736-42.

4. Rahman AS, Jaffri MSA, Raza SB, Sattar FA. The prevalence of gestational diabetes in patients attending Diabetic clinic at Sir Syed Hospital. Pakistan J Pharmacol 2007; 24: 37-42.

5. Fatima SS, Rehman R, Alam F, Madhani S, Chaudhry $B$, Khan TA. Gestational diabetes mellitus and the predisposing factors. J Pak Med Assoc 2017; 67: 2615 .

6. Ornoy A. Prenatal origin of obesity and their complications: Gestational diabetes, maternal overweight and the paradoxical effects of fetal growth restriction and macrosomia. Reprod Toxicol 2011; 32: 205-12.

7. Sukumar N, Venkataraman H, Wilson S, Goljan I, Selvamoni S, Patel V, et al. Vitamin B12 status among pregnant women in the UK and its association with obesity and gestational diabetes. Nutrients 2016; 8: 768.

8. De Sisto CL. Prevalence estimates of gestational diabetes mellitus in the United States, pregnancy risk assessment monitoring system (PRAMS) 20072010. Prevent Chron Dis 2014; 11: 1-9.

9. Khan A, Shafiq I, Hassan Shah M. Prevalence of vitamin B12 deficiency in patients with type II diabetes mellitus on metformin: A study from Khyber Pakhtunkhwa. Cureus 2017; 9(8):e1577.

10. Nizamani GS, Memon IA, Memon A, Khoharo HK. Vitamin B12 deficiency with megaloblastic anemia: An experience at Tertiary Care Hospital of Sindh. J Liaquat Uni Med Health Sci 2014; 13 (01): 13-17.

11. Finkelstein JL, Layden AJ, Stover PJ. Vitamin B-12 and perinatal health. Adv Nutr 2015; 6:552-63.

12. Rush E, Katre P, Yajnik C. Vitamin B12: One carbon metabolism, fetal growth and programming for chronic disease. Europ J Clin Nutr 2014; 68: 2-7.

13. Butt A, Malik U, Waheed K, Khanum A, Firdous S, Ejaz $\mathrm{S}$, et al. Low serum cobalamin is a risk factor for gestational diabetes. Pakistan J Zool 2017; 49(6): 1963-8.

14. Behan J. New ADA guidelines for diagnosis, screening of diabetes. Adv Labor 2017; 1(1):20-3. 
15. Mindiola AL, Fernandez HM, Arciniegas DR, Regino WO. Vitamin $B_{12}$ deficiency associated with consumption of proton pump inhibitors. Rev Colomb Gastroenterol 2017; 32 (3): 197-201.

16. Stewart CP, Christian P, Schulze KJ, Arguello M, LeClerq SC, Khatry SK, West KP, Jr. Low maternal vitamin B-12 status is associated with offspring insulin resistance regardless of antenatal micronutrient supplementation in rural Nepal. J Nutr 2011; 141:1912-7.

17. Krishnaveni G, Hill J, Veena S, Bhat D, Wills A, Karat $\mathrm{C}$, et al. Low plasma vitamin B12 in pregnancy is associated with gestational 'diabesity'and later diabetes. Diabetologia 2009; 52: 2350-8.

18. Knight BA, Shields BM, Brook A, Hill A, Bhat DS, Hattersley AT, Yajnik CS. Lower circulating B12 is associated with higher obesity and insulin resistance during pregnancy in a non-diabetic white British population. PLoS One 2015; 10: e0135268.

19. Chapman L, Darling A, Brown J. Association between metformin and vitamin B 12 deficiency in patients with type 2 diabetes: A systematic review and metaanalysis. Diabet Metabol 2016; 42: 316-27.
20. Karimi F, Omrani GR, Changes in serum levels of vitamin B12, folic acid and homocysteine in patients with type 2 diabetes before and after treatment with metformin. Asian J Med Pharm Res2016; 6: 46-52.

21. Valdés-Ramos R, Ana Laura GL, Beatriz-Elina MC, Alejandra-Donaji BA. Vitamins and type 2 diabetes mellitus. Endocr Metab Immun Disord Drug Targ 2015; 15: 54-63.

22. Mansell T, Saffery $R$. The end of the beginning: Epigenetic variation in utero as a mediator of later human health and disease. Future Med 2017; 9: 21721.

23. Yajnik CS, Deshpande SS, Jackson AA, Refsum $H$, Rao S, Fisher DJ, et al. Vitamin B12 and folate concentrations during pregnancy and insulin resistance in the offspring: The Pune Maternal Nutrition Study. Diabetologia 2008; 51: 29-38.

\begin{tabular}{|c|c|c|c|}
\hline Sr. \# & Author(s) Full Name & Contribution to the paper & Author(s) Signature \\
\hline 1 & Saher Fatima & $\begin{array}{l}\text { Literature review, Concept, Materials handling, } \\
\text { Interpretation lab investigations, Manuscript } \\
\text { write up, Proof reading. }\end{array}$ & \\
\hline 2 & Sadia Saeed & $\begin{array}{l}\text { Concept, Materials handling, Interpretation } \\
\text { lab investigations, Manuscript write up, Proof } \\
\text { reading. }\end{array}$ & क \\
\hline 3 & Syeda Fariha Hasnny & $\begin{array}{l}\text { Literature review, Materials handling, } \\
\text { compilation of resutls, statistical analysis, } \\
\text { Manuscrupt write up, Proof reading, }\end{array}$ & 3 \\
\hline 4 & Nathumal Maheshwari & & \\
\hline 5 & Urooj Tabassum & $\begin{array}{l}\text { materials, compilation of results, Statistical } \\
\text { analysis, manuscript write. } \\
\text { Concept, Materials handling, Collection of } \\
\text { materials, compilation of results, Statistical }\end{array}$ & 1 \\
\hline 6 & Arshad Ali & $\begin{array}{l}\text { analysis, manuscript write. } \\
\text { Concept, materials handling, Interpretation } \\
\text { lab investigations, Manuscript write up, Proof } \\
\text { reading. }\end{array}$ & \\
\hline
\end{tabular}

